I Instituto Federal de Educação, Ciência e Tecnologia do Rio de Janeiro,

Campus Eng. Paulo de Frontin, Rio de Janeiro, RJ, Brasil

barrosfelipe@gmail.com

Felipe Barros'

\title{
ARQUIVOS E OBJETOS SONOROS ETNOGRÁFICOS: A COLEÇÃO FONOGRÁFICA DE LUIZ HEITOR CORRÊA DE AZEVEDO
}

\section{INTRODUÇÃo}

Ao comentar a invenção do fonógrafo, Thomas Alva Edison (I878, apud Brady, I999) apresentava sua nova máquina (talking machine) como instrumento capaz de "capturar e preservar ondas sonoras fugitivas". Pensando em seu aspecto físico, Edison entendia o som como algo fugitivo e efêmero. O som (pela explicação da física) se manifesta pela movimentação de um corpo que produz rápidas vibrações no ar; um fenômeno que rapidamente se dispersa e se perde. A novidade da invenção de Edison estava na possibilidade de se registrar (gravar) e reproduzir (ou, melhor, escutar) um acontecimento sonoro passado, fosse performance musical, discurso ou conversa (Sterne, 2003).

O aparelho de Edison era um aprimoramento de outras tecnologias já desenvolvidas, como o vibroscópio, de Thomas Young, e o fonoautógrafo, de Leon Scott. Essas máquinas produziam representações gráficas do som, gravando-o em cilindros de diferentes materiais; eram, porém, incapazes de reproduzir o que haviam registrado. O fonógrafo de Edison funcionava de modo semelhante ao dos instrumentos de seus antecessores. Sua estrutura consistia em uma membrana acoplada a um bocal coniforme que captava a vibração do ar produzida por um evento sonoro (como um discurso feito próximo ao cone) e a convertia em impulsos mecânicos que faziam vibrar uma agulha em contato com um cilindro coberto por folha de estanho e girado manualmente por uma manivela. Conforme o cilindro era girado, a agulha criava sulcos em sua superfície. A 
inovação do aparelho de Edison estava no fato de que, ao final da gravação, trocada a agulha por outra de tipo diferente e girado o cilindro na direção contrária, era possível reproduzir o som gravado.

A primeira versão do fonógrafo de Edison possuía inúmeras falhas que prejudicavam sua popularização. Nos anos seguintes, o gravador passou por aprimoramentos feitos por Edison e outros inventores, como Graham Bell e Charles Tainter. O estanho dos cilindros foi substituído por cera, e, posteriormente, os cilindros deixaram de fazer parte da estrutura mecânica do aparelho e puderam ser substituídos, ocorrendo assim a separação entre o dispositivo de gravação (o gravador) e o suporte onde o som era gravado (o cilindro). Foram inventadas técnicas de reprodução dos cilindros, permitindo que uma gravação fosse copiada e comercializada. Diminui-se o tamanho do equipamento, tornando-o portátil, e o tempo de gravação de um cilindro aumentou para cerca de três minutos de gravação (Sterne, 2003).

Cerca de dez anos depois da invenção do fonógrafo de Edison, em I887, também nos Estados Unidos, Berliner lançava uma tecnologia diferente que competiria com o gravador de Edison: o gramofone. Nesse caso, o processo mecânico de gravação utilizado também era semelhante ao do antecessor. A grande diferença estava no suporte onde era impressa a gravação, que passou a ser feita em discos de acetato, vinil, de carvão e também cera. Os discos do gramofone podiam ser usados de ambos os lados, e sua reprodução em escala industrial era mais fácil e eficiente, possibilitando produções em larga escala com custo mais baixo. Além disso, o gramofone possuía mecanismo que funcionava como um relógio de corda e garantia a regularidade na rotação dos discos, bem como, consequentemente, a acuidade da gravação e da reprodução (Sterne, 2003).

Equipamento mecânico e portátil capaz de reproduzir o som e de replicá-lo em cópias, não é de estranhar que pouco tempo após sua invenção, os gravadores (fosse o fonógrafo de Edison ou o gramofone) tivessem sido adotados por etnógrafos em suas pesquisas de campo. No final do século XIX, o fonógrafo/gramofone já se tornara um instrumento de registro/documentação utilizado por naturalistas, linguistas, viajantes, folcloristas e psicólogos interessados em sociedades "não civilizadas" (Araújo, 2008). Fewkes (Brady, I999), nos relatos de sua viagem ao Maine, já defendia o uso do equipamento como o instrumento mais adequado para interessados em documentar formas verbais e expressões musicais. Mauss (I 926) em seu Manuel d'ethnographie mencionou o "método fonográfico" como uma das formas de observação e produção de dados em campo. Na primeira expedição ao estreito de Torres (I 988), o grupo de pesquisadores britânicos liderado por Haddon levou um fonógrafo de Edison para documentar a fala e a música nativas (Stocking, I983). Nos EUA, folcloristas como John A. Lomax e Robert Gordon utilizavam o equipamento para registrar canções, lendas e poemas. O mesmo era feito por etnólogos e antropólogos como Herskovits e Frances Densmore, ligados ao Bureau of American Ethnology. No Brasil, nas primeiras décadas do século XIX, Koch-Grünberg e 
Roquette-Pinto, em expedições distintas, levaram gravadores, produzindo os primeiros registros fonográficos do mundo ameríndio (Pereira \& Pacheco, 2008; Galucio, 2009)

Ainda no final do século XIX, na Europa, foram criados importantes arquivos fonográficos para guardar a documentação produzida em campo ${ }^{\mathrm{I}}$ como, por exemplo, o arquivo fonográfico da Academia Imperial de Ciências em Viena, em I899, e o arquivo sonoro da Société d'Anthropologie de Paris, em I900. Ambos tinham como objetivos gerais a documentação acústica de idiomas e dialetos europeus ou não europeus; o registro de músicas do mundo; o registro de falas, frases e discursos de personalidades célebres (Pinto, 2004; Netll, 2005). Nesses locais a documentação sonora coletada em campo era guardada, analisada e transcrita.

No caso específico das coleções de música, foram relevantes as experiências de registro sonoro e colecionamento de músicas ao redor do mundo feitas dentro do Departamento de Psicologia da Universidade de Berlim (e seu arquivo fonográfico) que, anos depois, serviram como modelo para outros acervos em diversos países. Em I900, Carl Stumpf (chefe do Instituto de Psicologia) fez gravações, medições de instrumentos musicais e experimentos de percepção musical com músicos tailandeses que visitavam Berlim. Interessado na fisiologia das percepções sensórias (psicoacústica), o estudo de Stumpf apontava que noções da música ocidental, tais como "desafinação" ou "tonalidades", eram culturalmente constituídas (Pinto, 2004; Araújo, 2008).

Erich Moritz von Hornbostel (I877-I935), aluno de Stumpf, ampliou as atividades do arquivo e transformou o Berliner Phonogrammarchiv em um centro de referência em estudo da música. Um dos projetos de Hornbostel era comparar os mais diferentes sistemas musicais, e, assim, ele solicitou auxílio de outros pesquisadores e enviou fonógrafos para ser utilizados em expedições etnográficas em diversas regiões do mundo. ${ }^{2}$ Dessa empreitada participaram nomes célebres da antropologia, como Evans-Pritchard e Boas (Brady, I999; Araújo, 2008; Pinto, 200I, 2004; Netl, 2005).

Do outro lado do Atlântico, o projeto de Hornbostel reverberou em ações de pesquisadores brasileiros e norte-americanos. No Brasil, como comentado por Pinto (2004), Mário de Andrade solicitou o empréstimo do fonógrafo ao arquivo alemão para realizar gravações de campo. O pedido foi atendido, e o aparelho recebido em I937, sendo utilizado para registro de cantos de candomblé baiano, feitos pela cantora e violonista Olga Praguer Coelho. No ano seguinte, Mário de Andrade dispensaria o fonógrafo alemão e utilizaria um gramofone em sua célebre Missão de Pesquisas Folclórica, organizada enquanto esteve à frente do Departamento de Cultura da cidade de São Paulo (Toni, I985; Sandroni, 2008). As gravações feitas durante a missão compuseram o arquivo da Discoteca Pública Municipal (São Paulo), instituição idealizada por Mário de Andrade, em I935, e que, anos depois, se tornaria a Discoteca Oneyda Alvarenga; um dos mais importantes arquivos fonográficos do país. 
Nos Estados Unidos, na década de I930, o ex-assistente de Hornsbostel, George Herzog, contou com apoio de Franz Boas (seu professor) para organizar o Arquivo de Música Folclórica e Primitiva da Universidade de Columbia. Posteriormente, Herzog contribuiu na fundação do que viria a ser o importante Archives of Tradional Music da Universidade de Indiana. Desdobrando, os trabalhos de Herzog, o etnomusicólgo George List estruturou o arquivo de Indiana a partir do modelo do arquivo fonográfico da Academia Imperial de Ciências, em Viena. Após Herzog e List, o arquivo de Indiana teve entre seus diretores relevantes etnomusicólogos, como Frank Gillis, Anthony Seeger e Ruth Stone (Brady, I999; Indiana, 2017).

Ainda nos Estados Unidos, antes da experiência de Herzog em Indiana, outro arquivo de extrema relevância para as discussões deste artigo foi organizado nos I920: o Archive of American Folk Song (AAFS). A instituição fazia parte da Divisão de Música da Biblioteca do Congresso Norte-Americano, sendo responsável por coleta e arquivamento de canções folclóricas. A fundação do AAFS data de I928, quando Carl Engel - então chefe da Divisão de Música da Biblioteca do Congresso - decidiu construir um arquivo destinado a reunir e preservar poemas e melodias folclóricas que, em sua opinião, estavam em risco de desaparecimento frente à disseminação do rádio e, paradoxalmente, do próprio fonógrafo (Hardin, 2004).

Robert W. Gordon foi o primeiro diretor do AAFS e responsável pela concepção das ações da instituição e da constituição de um setor dedicado à música e à poesia folclórica norte-americanas. Gordon tinha ampla experiência em coleta de música folclórica e, desde a primeira década do século XX, viajou por conta própria pelos Estados Unidos gravando canções em um fonógrafo de Edison. Seu desejo era criar um grande arquivo sonoro da América, e o AAFS veio como uma forma de institucionalização desse projeto.

Em I933, Gordon havia deixado a posição de diretor, assumindo John Lomax, também experiente colecionador de música folclórica. Durante os dez anos que ficou à frente da direção do AAFS realizou inúmeras viagens etnográficas para gravações de campo junto com seu filho, Alan Lomax. Os Lomax estabeleceram a documentação da "cultura tradicional" como atividade central dos AAFS. Em I 937, Alan passaria à frente da instituição, com o cargo de "assistente no comando" (Hardin, 2004). Entre I 937 e I 942, Lomax estruturou um moderno laboratório de gravação e comandou expedições de coleta de música e poesia por todo o país, utilizando um caminhão especialmente equipado para essa tarefa. Além disso, foi responsável pela publicação de discos de música folclórica norte-americana e pela elaboração de programas de rádio feitos com o objetivo de divulgá-la (Hardin, 2004).

Alan também levou adiante um projeto iniciado em I933 por seu pai, que permitia o empréstimo de equipamentos de gravação para pesquisadores, seguindo um plano semelhante ao do arquivo de Berlim. Em contrapartida ao uso 
do equipamento, os pesquisadores deveriam depositar no AAFS uma cópia de todo o material sonoro produzido em suas etnografias. Essa estratégia levou a significativo aumento da coleção de discos e criou uma comunidade de pesquisadores ligados ao AAFS. Devido à expertise de seu laboratório de gravação e ao sucesso do projeto de empréstimos de equipamento, rapidamente o AAFS se tornou uma referência em coleta e arquivamento de material etnográfico fonográfico, sendo procurado por folcloristas, etnólogos, linguistas e antropólogos, como William Fenton e Melville Herskovits, por exemplo (Hardin, 2004).

Nos anos 1940, Luiz Heitor Corrêa de Azevedo, professor de folclore na Escola Nacional de Música (atual escola de música da UFRJ), participou do projeto de Lomax, utilizando equipamentos de gravação e recursos financeiros concedidos pela Biblioteca do Congresso Norte-Americano para o que chamou de "viagens etnográficas" aos estados de Goiás (I942), Ceará (I943) e Minas Gerais (I944), em que realizou extensa documentação fonográfica de música folclórica brasileira.

Nessas viagens, Luiz Heitor produziu 3 I I fonogramas, entre outros registros, que posteriormente foram enviados para o AAFS. No Brasil, a documentação sonora das "viagens etnográficas" estimulou a fundação do Centro de Pesquisas Folclóricas (CPF), localizado na Escola Nacional de Música, no Rio de Janeiro, que se tornou o primeiro centro universitário dedicado aos estudos do folclore musical no país, guardando toda a documentação sonora produzida durante as viagens etnográficas como também outras coleções relacionadas ao folclore musical, incorporadas à coleção ao longo dos anos. No CPF, essas gravações serviram como fontes para projetos de pesquisa sobre música brasileira, sendo transcritas em partituras e em seguida analisadas (mediante medições de escalas musicais, afinações, reincidência de padrões melódicos e células rítmicas, instrumentação etc...).

Além da relação com o AAFS de Alan Lomax, o CPF criado por Luiz Heitor também dialogava com outro projeto de documentação fonográfica e arquivo: a já mencionada missão de pesquisas folclóricas de I938 (Toni, I985) e o acervo fonográfico da discoteca municipal de São Paulo. Como demonstraram outros pesquisadores (Aragão, 2005; Mendonça, 2007), na preparação das viagens, Luiz Heitor manteve diálogo com Mário de Andrade por meio de cartas, buscando registrar a música de regiões do país que não tivessem sido exploradas pelas missões folclóricas de I938 (Barros, 2013).

Além disso, o arquivo de Luiz Heitor atendia, de certo modo, à proposta política e estética elaborada por Mário de Andrade (I972) em Ensaio sobre a música brasileira, que tinha o folclore como elemento-chave de modernização da música de concerto brasileira. Luiz Heitor pretendia utilizar seus documentos sonoros como material didático, introduzindo alunos de graduação em composição no universo do "folclore musical" brasileiro e os estimulando a incorporar elementos estéticos musicais do folclore representados em suas gravações etnográficas. 


\section{OS SENTIDOS DOS ARQUIVOS ETNOGRÁFICOS FONOGRÁFICOS}

No campo da etnomusicologia, é consenso entre os autores que o advento do fonógrafo foi fundamental para o desenvolvimento de estudos de músicas não ocidentais ou cuja transmissão se baseava na oralidade (Araújo, 2008; Merrian, I964; Netll, I988; Pinto, 200I, 2004; Seeger, I986, 200I). Foi o fonógrafo que permitiu o registro de músicas não europeias e/ou ágrafas feito durante expedições etnográficas, e foi por meio do fonograma que diferentes tipos de performance puderam ser transpostos de seu lócus de origem - fossem essas regiões afastadas das metrópoles no âmbito rural ou as próprias colônias europeias - para instituições acadêmicas localizadas em centros urbanos. Em outras palavras, o fonograma foi o meio pelo qual pesquisadores que até então não participavam da etapa etnográfica da pesquisa tomaram contato com línguas, repertórios, "sistemas", "afinações" e "práticas musicais" de locais desconhecidos tanto em territórios nacionais (como no caso dos folcloristas) como em diferentes partes do mundo (no caso dos arquivos como os de Berlim e Indiana).

Os arquivos fonográficos etnográficos franquearam a aproximação de formas expressivas sonoras de territórios e contextos distantes. Nesses espaços, pesquisadores puderam emparelhar os diferentes sistemas musicais e linguísticos, fazendo análises e comparações entre eles. Posto isso, não é de estranhar que as teorias difusionistas, de aculturação, as propostas de mapeamentos culturais e estudos comparativos tenham, em um primeiro momento, inspirado as iniciativas de tais arquivos.

A constituição de diversos arquivos fonográficos demonstra também a força que tal tipo de registro assumiu nas metodologias de pesquisa e em instituições ao redor do mundo. Mediante parcerias e convênios, os arquivos contribuíram para a institucionalização de práticas e métodos tanto de registro como de arquivamento. O empréstimo de gravadores e disponibilização de recursos financeiros (como nos casos citados de Hornbostel e dos Lomax) permitiu que pesquisadores se valessem de tecnologias às quais, em tese, não teriam acesso via suas instituições.

As lógicas de arquivamento e propostas institucionais também se disseminaram por meio de tais convênios. Para constituir o acervo do Centro de Pesquisas Folclóricas, por exemplo, Luiz Heitor se espelhou na proposta institucional e nas práticas de colecionamento e catalogação do AAFS (Barros, 20I3). O mesmo fez Frank Gillis em relação à coleção da Universidade de Indiana, inspirando-se em práticas do arquivo fonográfico de Viena (Indiana, 20I7). Tais iniciativas configuraram redes de pesquisadores que, embora de áreas de atuação distintas ${ }^{3}$ e utilizando métodos também distintos, tinham um interesse comum nas formas expressivas que se manifestam de modo significativo pelo fenômeno sonoro.

Contudo, os estudos da música que vieram a se consolidar nos Estados Unidos como o campo da etnomusicologia problematizaram, de certo modo, o 
papel dos acervos fonográficos e do uso do fonograma em projetos de pesquisa etnográficas. A aproximação com as teorias antropológicas (Merrian, I964; Nettl, 2005) direcionou etnomusicólogos para o entendimento das práticas musicais como elementos relacionados à vida social e cultural ou que dela emergem. A proposta de uma antropologia da música feita por Alan Merrian (I964) enfatizou a importância da experiência em campo para a compreensão dos sentidos engendrados pelas práticas/performances musicais.

Os fonogramas não traziam dados necessários para o entendimento dos significados, simbolizações e relações sociais que envolviam determinada performance musical (Netll, 2005). As gravações fonográficas passaram a ser consideradas registros descontextualizados. Sob tal perspectiva, passou a ser questionada a relevância de estudos feitos exclusivamente em laboratórios ou arquivos e que se restringiam à análise de documentos sonoros. Antropólogos e etnomusicólogos deixaram de apenas consultar e analisar fonogramas guardados em arquivos, como era feito, por exemplo, nos estudos da musicologia comparada alemã (Pinto, 200I; 2004), deixaram seus gabinetes e passaram a ir a campo, produzindo (quase obrigatoriamente) suas gravações durante tal etapa da pesquisa (Seeger, 200I).

$\mathrm{Na}$ área da antropologia e etnomusicologia norte-americanas, a documentação fonográfica de campo não é mais entendida como mero recurso de coleta e/ ou registro de sons para posterior análise ou arquivamento visando à preservação. O gravador de som e o documento sonoro passam a ser utilizados como instrumentos que vão auxiliar a lembrança e a interpretação de experiências, de performances, rituais, na compreensão de línguas e em situações de interlocução vivenciadas no campo, tal como um caderno de campo. Ou seja, o gravador torna-se um recurso para a escrita do texto etnográfico. Tal como as fotos, as gravações passam a constituir documentação que vai ser acionada para demonstrar e ilustrar os objetos de estudo e legitimar, de certo modo, a experiência vivenciada pelo etnógrafo no campo (Clifford, 2002).

Deve-se considerar também o fato de, nesse momento, os gravadores já terem passado por diferentes aprimoramentos que diminuíam muitas limitações ao seu uso. A tecnologia de gravação mudou, e o suporte fonográfico mais comum era a fita magnética, em vez dos frágeis cilindros de cera e discos de acetato. Os gravadores tornaram-se mais portáteis e baratos; funcionavam movidos a baterias, e o tempo de duração de uma gravação aumentara significativamente. Desse modo, em certo grau, os dispositivos de gravação se tornaram mais acessíveis e eficientes e puderam ser usados mais facilmente e com mais regularidade ao longo de uma pesquisa (Makagon \& Neumman, 2009).

Os estudos sobre mudança musical que emergem nos anos I970 (Kartomi, I98I; Nettl, I985; 2006; Blacking, I979) demonstraram que as práticas musicais sofrem permanente processo de transformação que se manifestam nos mais variados aspectos estéticos sonoros, como prosódia musical, ${ }^{4}$ afinação, estilos 
de execução, na organologia, nos padrões de improvisação etc. Pesquisadores como Kartomi (I98I) e Nettl (1985; I996; 2006) assinalaram como transformações socioculturais levam a mudanças de formas expressivas musicais. Focando suas pesquisas nos efeitos do contato cultural e da modernização de regiões periféricas, Nettl (1985), por exemplo, investigou as mudanças geradas pela penetração da música de concerto ocidental em contextos coloniais (Nettl, I985; 2006). Seguindo outro caminho, Blacking (I979) observou como a mudança também pode ocorrer a partir de dinâmicas e valores internos aos próprios grupos. Em alguns casos, a transformação pode se dar a partir da agência direta de indivíduos, em outros, é motivada por mudanças cognitivas e processos de inovação locais. Para o autor, a mudança independe de profundas transformações sociais, e os grupos podem ter trajetória própria de inovações em seus sistemas musicais ao longo do tempo.

Se as práticas musicais são dinâmicas e sujeitas a transformações, o ato de as registrar em fonogramas passa a ser entendido como um recorte temporal e efêmero. Tal condição aponta para a impossibilidade de projetos institucionais que pretendem colecionar e mapear toda a produção musical de uma região como nas propostas já citadas de Robert W. Gordon e das primeiras elaborações do projeto de documentação do brasileiro Luiz Heitor. ${ }^{5}$

Sob tal perspectiva, o uso não problematizado de fonogramas poderia então contribuir para o estabelecimento de estereótipos culturais, já que, com o passar do tempo, o registro poderia deixar de ser representativo dos processos socioculturais e práticas musicais da região a que estava associado. Os arquivos dedicados ao mapeamento estariam então fadados à documentação ininterrupta; só assim poderiam dar conta de acompanhar os processos de inovação desenvolvidos nos mais variados contextos.

Nos anos I980, a reavaliação das formas de representação etnográfica, que se inicia com a antropologia interpretativa e se desdobra na chamada crítica pós-moderna (Clifford, 2002), leva a outra ressignificação dos papéis dos arquivos etnográficos (Cunha, 2004; Gonçalves, 2007) e, consequentemente, de toda a documentação etnográfica neles depositada (Seeger, 200I; 2003). Assume-se uma postura de estranhamento frente ao campo da antropologia, buscando entender contextos político-ideológicos e relações de poder em que estão inseridos o discurso e a prática da disciplina. Nesse momento de revisão, determinados pesquisadores se dedicam a explicar a constituição da antropologia a partir da produção de uma história crítica do campo (Stocking, I983). As coleções etnográficas presentes em museus e arquivos pessoais tornaram-se então o lócus ideal para estudo e construção de tais narrativas, proporcionando, de certo modo, um "retorno dos antropólogos aos arquivos" (Cunha, 2004; Gonçalves, 2007).

Além do viés histórico, o novo exame das coleções também vai ser motivado por questões epistemológicas que buscam entender as lógicas e relações sociais simbólicas e políticas que orientavam tais instituições. Os arquivos 
passaram a ser identificados como mediadores de processos políticos de construção de sentido a respeito da produção material de variados grupos sociais. Como colocado por Gonçalves (2007: 49), tais processos são complexos e envolvem um conjunto de ações, como "as formas de aquisição desses artefatos, o contexto social e cultural em que foram adquiridos, sua transferência para coleções, sua reclassificação e, não menos importante, suas formas de exposição". Os arquivos etnográficos passam a ser entendidos como espaços portadores de uma história sobre os diferentes modos de objetificação do “'outro' não ocidental" promovidos pelo campo da antropologia.

Fato curioso é que, apesar das várias mudanças de perspectiva sobre o papel da documentação fonográfica e dos acervos, etnomusicólogos e antropólogos não deixaram de produzir registros fonográficos sobre suas experiências de campo. Do mesmo modo, instituições como a Unesco continuaram financiando uma extensa coleção fonográfica de músicas do mundo, buscando representar e preservar a "diversidade musical mundial".

Num contexto pós-colonial e de revisão das consequências políticas das etnografias, entretanto, pesquisadores e arquivos começaram a lidar com questões éticas relacionadas à propriedade intelectual dos registros, como também da apropriação cultural. Esse quadro de questionamento se agravou a partir do momento em que fonogramas etnográficos começaram a circular fora do ambiente acadêmico, sendo incorporados pela indústria fonográfica e com usos distintos dos planejados pelos pesquisadores que os criaram (Seeger, 2003).

Como em outras áreas em que a etnografia é prática central, a crítica "pós-moderna" repercutiu no campo da etnomusicologia e reorientou a postura e os objetos de interesse dos etnomusicólogos. Cooley (I997), por exemplo, remodelou alguns aspectos da discussão "pós-moderna" e propôs uma mudança do foco da análise da representação (textos) para a experiência (trabalho de campo). Para ele, era necessário focar a atenção nas práticas de pesquisa de campo, desenvolvendo uma reflexão crítica sobre a presença do etnógrafo no campo e as consequências de suas ações. Esse seria também um caminho para alcançar melhor entendimento das formas de representação que surgem a partir do trabalho etnográfico.

Apesar de reconhecer a existência de uma bibliografia que analisa criticamente as formas de trabalho de campo da antropologia, Cooley (I 997) acreditava ser necessário investigar problemas específicos da pesquisa etnomusicológica. Para o autor, já nos anos I990, a etnomusicologia acumulava um histórico de experiências que indicavam modos próprios de fazer pesquisa de campo, como se envolver ativamente em performances musicais das culturas pesquisadas, trocar repertórios com seus informantes, assumir o lugar de aprendiz junto a um mestre, produzir representações de performances musicais utilizando gravações.

No Brasil, artigos (Zamith, I992; Travassos, 2003; Pinto, 2004) já assinalavam a importância das pesquisas de folcloristas que usaram gravadores para o 
desenvolvimento dos estudos etnográficos da música. Nos anos I990 um conjunto de trabalhos (Cavalcanti \& Vilhena, I990; Cavalcanti et al., I992; Vilhena, I997) havia reaproximado os estudos de folclore e as ciências sociais, demonstrando a histórica relação conflituosa e de disputa entre os dois campos - que levou a uma certa desvalorização dos estudos do folclore durante determinado período. Sobre a área da música, porém, Travassos (2003) indicava a proximidade direta da etnomusicologia brasileira com os estudos do folclore, argumentando que os folcloristas legaram seus objetos de estudos (as performances da cultura popular) aos etnomusicólogos, como também toda a documentação etnográfica por eles produzida, incluído o acervo de fonogramas elaborados pelos já mencionados Mário de Andrade e Luiz Heitor, entre outros.

\section{O PROJETO DE DOCUMENTAÇÃO LUIZ HEITOR CORRÊA DE AZEVEDO}

No contexto crítico sobre o papel dos arquivos e que aproxima os estudos folclóricos e a etnomusicologia, o acervo fonográfico de Luiz Heitor, construído por convênio com o AAFS, se mostra então excelente objeto para pensar lógicas e modos de fazer etnografia usando documentação fonográfica no Brasil e entender como se desenvolveram os estudos etnográficos em música no país.

Desde os anos I940, os documentos relacionados às viagens estiveram guardados na Escola de Música da UFRJ, no espaço do Centro de Pesquisas Folclóricas. Anos mais tarde, o acervo passaria para a guarda do Laboratório de Etnomusicologia da UFRJ, que manteve o conjunto documental composto por itens em papel (relatórios, projetos de pesquisa, documentos institucionais, cartas pessoais, cadernos de campo, fichas de descrição de gêneros musicais, recortes de jornais etc.), fotos e 3 I I discos de 78RPM. No começo dos anos 2000, diferentes pesquisadores (Aragão, 2005; Mendonça, 2007; Barros, 20I3) examinaram esse corpo documental a partir de diferentes perspectivas, contextualizando a produção de tal acervo e, de certo modo, auxiliando outros pesquisadores que vinham utilizando os escritos e fonogramas de Luiz Heitor como referência básica em suas pesquisas desenvolvidas majoritariamente no campo da etnomusicologia (Prass, 2013).

Luiz Heitor iniciou sua carreira como musicólogo, crítico musical e bibliotecário no antigo Instituto Nacional de Música (INM), ${ }^{6}$ dedicando-se posteriormente ao estudo do folclore musical. Em I939, assumiu a cadeira de professor de folclore musical na Escola Nacional de Música da Universidade do Brasil. Essa foi a primeira vaga dedicada aos estudos do folclore em uma universidade brasileira. O cargo foi concebido em I93I, durante as reformas dos currículos do INM elaborado por Mário de Andrade e Sá Pereira` (Zamith, I992). As mudanças propostas alteravam a estrutura do curso de graduação em música, buscando mais ampla "intelectualização" dos alunos e ruptura com a tradição romântica de formação de virtuoses.

Inicialmente a cadeira seria denominada etnografia da música, porém as mudanças propostas por Andrade e Pereira encontraram resistência dentro da 
instituição, e a reforma dos currículos não foi totalmente implementada naquele momento. Em I938, quando Sá Pereira assume a direção do INM, a cadeira de etnografia da música é finalmente criada, contudo, teve seu nome trocado para folclore nacional musical (Barros, 20I3). Apesar da troca de nome, a criação da disciplina estava em sintonia com o projeto estético modernista proposto por Mário de Andrade (1972) ${ }^{8}$ em Ensaio sobre a música brasileira, que, como dito, tinha as formas expressivas do folclore musical como peça-chave para o desenvolvimento de uma música nacional moderna de concerto.

Após assumir o cargo de professor, Luiz Heitor se dedicou intensamente ao estudo do folclore, participando da fundação da Comissão de Pesquisas Populares (CPP), junto com o próprio Mário de Andrade. Foi nessa comissão que Luiz Heitor teve as primeiras experiências de campo, coletando material do folclore urbano para uma exposição na cidade do Rio de Janeiro (Lira, I953).

Em I94I, Luiz Heitor viajou aos Estados Unidos a fim de prestar consultoria para um catálogo de compositores a ser editado pela Divisão de Música da União Pan-Americana, instituição dirigida por Charles Seeger. ${ }^{9}$ Durante a viagem, Luiz Heitor visitou o AAFS e conheceu Alan Lomax e seu laboratório de gravação. Nessa visita, surgiu a proposta de convênio entre a instituição norte-americana e a Escola de Música, tendo como plano inicial a vinda de Lomax ao Brasil, em I943, para documentação da música folclórica brasileira. Porém, com a entrada dos Estados Unidos na Segunda Guerra Mundial, Lomax se envolve na produção de atividades culturais para o Exército americano (Lomax, 2003), desistindo da viagem.

O projeto passou a ser de responsabilidade de Luiz Heitor e de um técni$\mathrm{CO}^{\mathrm{IO}}$ contratado para auxiliá-lo nas gravações. O AAFS emprestou todos os equipamentos necessários (gravadores, agulhas, discos e geradores elétricos) e disponibilizou U\$ I.450 para custos diversos e remuneração dos músicos participantes. Pelo convênio, os originais dos discos deveriam ser enviados ao AAFS em Washington, e cópias ficariam guardadas no Brasil. ${ }^{\text {II }}$

Inicialmente, Luiz Heitor pretendia percorrer Rio de Janeiro, Minas Gerais e o Nordeste do país nos meses de abril, maio e junho de I942, porém enfrentou problemas com a liberação do equipamento de gravação na alfândega brasileira e no pagamento do financiamento. Esses imprevistos alteraram o planejamento inicial, e o projeto foi executado, como já mencionado, em três anos, envolvendo viagens para Goiás (I 942), Ceará (I 943) e Minas Gerais (I944).

\section{FONOGRAMAS COMO OBJETOS ETNOGRÁFICOS}

Documentos fonográficos produzidos por pesquisas etnográficas podem ser considerados objetos sonoros que possuem certas particularidades. Sua materialidade aparente está em seus suportes (os discos de 78RPM); a importância, contudo, de tais objetos se dá pelas informações sonoras que carregam; algo não tão visível. Como é possível apreender um canto ou um toque de instrumento fixado em um fonograma como "objeto" de uma investigação científica? Torna-se neces- 
sário entender as circunstâncias de produção e os sistemas de valores científicos que permitem tornar o registro sonoro um duplo, equivalente a tipos de performances musicais que, na época, só poderiam ser observadas diretamente em seu contexto de prática.

Para Fabian (2007) um objeto etnográfico é um artefato que foi removido de seu contexto de produção e consumo e, em seguida, inserido em um sistema de classificação científica. Para o autor, a relevância de um objeto etnográfico não decorre totalmente do valor ou dos sentidos que possui em seu contexto de origem. Em determinados casos, os objetos etnográficos podem ser peças consideradas comuns, de uso regular, como jarras, panos, utensílios etc. A "importância etnográfica" que assume está diretamente relacionada aos sistemas de classificação operados pelo pesquisador.

Os objetos etnográficos são criações dos etnógrafos. Tornam-se etnográficos a partir do momento em que assim são definidos; "são segmentados, descolados de seus contextos e carregados para outro lugar" (Kirshenblat-Gimblett, I998: 387). A criação de um objeto etnográfico é uma espécie de ressignificação que pressupõe, em algum grau, sua descontextualização. A partir do olhar do etnógrafo, o artefato é identificado como portador de um tipo de conhecimento específico; torna-se representativo de práticas sociais, de simbolizações rituais, de pensamentos míticos etc. Torna-se também um objeto de interesse científico relevante, pois expressa - ou a partir dele podem-se entender - determinados processos sociais, valores e sistemas de pensamento.

Nesse processo de transformação, os sistemas de classificação científica e as coleções etnográficas em que são guardados desempenham importante papel de mediação. As coleções fazem operações estéticas e políticas, produzindo valores e sentidos; dão forma aos objetos e estabelecem unidade e continuidade entre elementos oriundos de contextos distintos. As coleções são verdades situadas, fruto de processos de seleção, e condicionadas por sistemas específicos de pensamento e crença.

Em um projeto de documentação fonográfica, um primeiro ponto a se considerar é a descontextualização promovida pelo próprio processo de gravação. As performances musicais documentadas por Luiz Heitor possuíam morfologias específicas, ocorriam em locais determinados, em ambientes acústicos específicos, obedeciam à sazonalidade etc. O processo de gravação, de certo modo, remodela tais performances, adequando-as aos recursos técnicos e tecnologias disponíveis e às condições de pesquisa.

A maioria dos registros de Luz Heitor, por exemplo, não foi feita no contexto de atuação dos cantadores e tocadores. Visando obter melhor qualidade de registro e evitar ruídos externos, Luiz Heitor utilizava ambientes preparados para a gravação, como estações de rádio, salões de clube, residências de colaboradores e restaurantes. Primeiro, ele se encontrava com seus "informadores", acertava o valor a ser pago pelo registro e agendava uma sessão de gravação. Os participantes compareciam então ao local combinado, no dia e hora marcados, para o registro. 
O tempo disponível de gravação também era um limitador. Os discos de 78RPM utilizados eram capazes de registrar no máximo cinco minutos de gravação em cada lado. Desse modo, as performances deviam ser adaptadas a esse espaço de tempo ou interrompidas para a troca de lado do disco. Na coleção, existem registros que se desdobram em vários discos, como no caso da gravação dos congos, em Fortaleza. Em algumas modas de viola, o tocador executa a música somente uma vez, sem repetições de verso ou improvisos, garantindo o registro da poesia no tempo disponível.

Na pesquisa de Luiz Heitor, a produção de fonogramas e seu colecionamento estavam ligados a um processo de "objetificação cultural" (Handler, I984) que buscava produzir um entendimento sobre o que seria a identidade musical nacional. Como colocado no texto do autor, "Temos de proceder ao arquivamento do que ainda nos resta, para servir de amostra aos pósteros e fornecer aos pesquisadores elementos para melhor compreender o processo de formação do homem brasileiro e da sua música" (Azevedo, i943: 6, grifo meu).

Para Luiz Heitor, a "música do homem brasileiro" não havia sido amplamente compreendia pelos pesquisadores da época. Essa compreensão se daria então pelo colecionamento de diferentes expressões e sua análise científica. ${ }^{12}$ Seguindo o pensamento de Mário de Andrade (1972), Luiz Heitor acreditava, por exemplo, ser possível a constituição de uma coleção que seria um mapa nacional onde estariam representadas zonas de influência musical e cultural das três raças formadoras do Brasil - indígena, negra e europeia (Aragão, 2005). Na citação abaixo, Luiz Heitor comparou as áreas de "influência cabocla" - Nordeste do país - e de "influência negra":

No canto caboclo, tonalidade e simetria rítmica se diluem numa faixa melódica extremamente livre, em que altura dos sons, seu grupamento em forma de escala e sua divisão métrica nada têm de comum com o sistema empregado pela música do Ocidente, nos tempos modernos. O canto dos negros, ao contrário, melodicamente dócil à supremacia europeia, caracteriza-se pela mais estrita simetria rítmica, dentro da deslocação de acentos representada pela sua constante sincopação. Quanto aos instrumentos de música, o uso exclusivo de percussão, ou sua violenta irrupção no conjunto musical, assinala a presença de elementos negros em nossa folcmúsica (Azevedo, I950: 18).

Como visto, portanto, Luiz Heitor associou elementos da estética musical e categorias étnicas. Em outros textos, também ficará evidente a relação entre elementos musicais, éticos e marcadores geográficos espaciais, como, por exemplo, as diferentes regiões do país. A relação entre etnia, marcadores espaciais e elementos estéticos expressivos musicais (tal como sistematizados pela musicologia) se dava a partir de uma operação intelectual em duas partes.

Na primeira, durante a pesquisa de campo, Luiz Heitor preenchia dois tipos de fichas. O primeiro, que trazia informações sobre os tocadores e incluía foto, passou por algumas alterações ao longo da pesquisa, mas, basicamente, 
continha estes itens: nome, idade, naturalidade, cor (às vezes pela categoria raça), profissão, nível de escolaridade, local e época em que aprendeu a melodia (Azevedo, I943: 28). No segundo tipo de ficha anotavam-se informações sobre a performance e o documento sonoro gravado, como título da música, gênero (moda de viola, congos, vissungu etc.), data e local, circunstância (descrição da sessão de gravação incluindo informadores e demais participantes), instrumentação utilizada pelos músicos durante a gravação (por exemplo, duas vozes e uma viola), notas eventuais.

A próxima etapa era feita no arquivo, já com os fonogramas devidamente catalogados. Nesse momento, a tarefa era fazer análises musicológicas das músicas registradas, medindo escalas musicais, reconhecendo padrões melódicos, células rítmicas reincidentes, afinação dos instrumentos de corda e instrumentação etc.

Tendo esses dados disponíveis, seria possível associar os perfis pessoais dos tocadores gravados e as características musicais de sua performance ou identificar recorrência de elementos estéticos musicais em determinada região do país. O pressuposto era que as formas musicais expressariam por si as características étnicas e da região dos tocadores documentados.

Como já mencionado, os objetos etnográficos sonoros de Luiz Heitor interessavam porque poderiam servir para a construção de um entendimento da música nacional. A pesquisa, assim, abrangia uma escala ampla, de modo que suas viagens não eram consideradas a partir das cidades ou bairros de Goiânia, Fortaleza ou Diamantina, mas das diferentes regiões do Brasil (Centro-Oeste, Nordeste e Sudeste). Seu interesse não era em grupos ou práticas específicas, mas sim em músicas de "regiões" que estariam representadas nos locais visitados.

Além de representar elementos étnicos-regionais e constituir "fragmentos" da cultura popular ou folclore, os objetos etnográficos sonoros de Luiz Heitor possuíam valor científico estabelecido por ideais de "autenticidade" e "pureza", advindos do "isolamento". Tal como outros intelectuais ligados ao movimento folclórico, Luiz Heitor acreditava que a cultura popular era algo "puro" e, por isso, dotada da capacidade de expressar a identidade de um povo. Essa pureza era oriunda do isolamento de comunidades que estavam distanciadas das elites cosmopolitas, dos valores burgueses, da classe operária e dos meios de comunicação, que eram, todos, marcados por traços culturais internacionais. Luiz Heitor considerava que as "camadas mais recônditas da população" eram as que forneciam "o puro substractum do Folclore", já que se achavam "protegidas pelo isolamento, pela introspecção ou retrospecção cultural que é a força viva e original do saber e das artes populares" (Azevedo, I943: 5).

O pesquisador entendia o processo de modernização e a influência dos meios de comunicação como algo nocivo. Em seu texto de introdução à primeira publicação do Centro de Pesquisas Folclóricas, apontou o rádio e os fluxos migratórios para o oeste brasileiro como alguns dos principais responsáveis pelas "modificações na linfa sensibilíssima do folclore" (Azevedo, I943: 5): 
O rádio, cuja força de penetração não conhece limites, se encarrega de propagar seu tipo de música urbana pelo sertão. E a marcha para o Oeste, a zona da guerra nordestina e a batalha da borracha, no Amazonas, deslocam populações, alargam as vias de penetração, desequilibram o ritmo sonolento de certos costumes secularmente inalterados.

No início de suas pesquisas, por exemplo, Luiz Heitor avaliou que nem todas as performances documentadas eram apropriadas. Se as formas expressivas musicais podiam expressar o nacional, por outro lado, também podiam expor os processos de modernização do país e sua deterioração. Para ele, algumas gravações já apresentavam traços de influência da indústria do rádio e do disco, e, por isso, teriam "menor valor" (Azevedo, I950: 3) já que nessas performances, os tocadores utilizavam recursos estilísticos musicais e repertórios considerados inadequados.

No texto abaixo, Luiz Heitor escreve sobre o desapontamento que teve frente alguns músicos, em Goiás.

Há um ano, em Goiás, recolhendo a arte tradicional dos cantadores e dançadores daquelas longínquas paragens, pude constatar que alguns deles procuravam substituir o seu estilo autêntico, herdado de muitas gerações, pelas falsificações de uma arte pseudocaipira, alimentada, nas cidades, pelo comercialismo do rádio e do disco (Azevedo, I950: 3).

No texto "Preâmbulo", o folclorista chega a desqualificar alguns dos seus documentos gravados no Ceará.

Nem todos os documentos que colhemos têm igual valor folclórico. A propagação de sambas e marchinhas de carnaval, pelas grandes radiodifusoras nacionais, bem como a influência dos artistas que cultivam programas de gênero caipira, nessas mesmas radiodifusoras, atingiram a inauguração poético-musical de certos bardos da região, que pensam elevar a sua arte, moldando-a pelos padrões mais cultos que vêm do Rio ou de S. Paulo. De um modo geral ficam enfraquecidos por essas circunstâncias todos os cantos de Chico Onça e Micuim; os duos de viola de Alagoano e Brasil Primeiro; e os trechos executados pelo conjunto instrumental de Augusto Catarino Santos, Silvio de Souza e Felipe Andrade (Azevedo, I953: 3).

Por outro lado, agindo contra o processo de modernização, Luiz Heitor interveio no campo, remontando performances que considerava relevantes "do ponto de vista folclórico", mas que haviam sidos abandonadas pelos grupos visitados. A descrição do boi de reis no artigo "Autos tradicionais do Ceará" (Azevedo, I953) pode ser um bom exemplo.

Boi de Reis - Em I943, devido aos rigores da seca que afligia o estado, o povo não havia "folgado" com seu divertimento predileto. Graças à cooperação do nosso jovem amigo Edison Araújo, cujos conselhos e experiência foram preciosíssimos para nós, e despendendo algumas centenas de cruzeiros para custear as máscaras e gratificar componentes, obtivemos um grupo que, por uma clara noite de luar, diante da casa do major Lucas Araújo, num quadrângulo demarcado e bem 
regado, para evitar o levantamento de poeira ofereceu-nos um espetáculo tão desejado (Azevedo, I953: 45-46).

Cabe frisar que Luiz Heitor chegara à cidade de Itapipoca no dia I 8 de janeiro, I 2 dias depois da data que identifica como a que tradicionalmente se comemora o dia de reis). Sendo, porém, o "espetáculo" muito "desejado", o pesquisador articulou as condições necessárias para que a performance fosse montada e devidamente registrada.

Procedimento semelhante foi adotado em relação a outras gravações feitas no Ceará. O registro de viagem mostra que o grupo de congos gravado em Fortaleza já não saía às ruas há cinco anos. Luiz Heitor articulou a reunião do grupo e sua performance com o intuito de gravá-la. Em Minas Gerais, também remontou performances quando a sazonalidade não coincidia com seu período de viagem. As Pastorinhas de Natal, as performances da festa do Divino Espírito Santo e um ritual funerário foram todos "encenados", exclusivamente, para o registro fonográfico.

Kirshenblat-Gimblett (I998) pontua que os objetos etnográficos são produzidos simultaneamente ao fazer científico; a ciência etnográfica faz seus objetos ao mesmo tempo em que se faz. Se os objetos estão alinhados com os valores científicos que motivam sua produção, as mudanças de perspectiva teórica influenciam diretamente a estética e validade dos documentos.

Um aspecto interessante no caso de Luiz Heitor é que ao longo do projeto de pesquisa sua perspectiva sobre o que seria a música folclórica vai mudando e, do mesmo modo, os documentos registrados. Inicialmente, percebe-se que sua concepção de folclore está associada aos gêneros musicais, repertórios ou estilos de performance descritos e determinados por pesquisadores que o antecederam, como Guilherme de Mello, Renato Almeida e o próprio Mário de Andrade. A análise das correspondências, contudo, demonstra que seu conceito de "música folclórica" vai-se "flexibilizando". Em Minas Gerais, Luiz Heitor gravou mais livremente, sem se preocupar com o "valor folclórico" das performances ou a adequação dos repertórios ao quadro canônico das "músicas folclóricas do Brasil", da época. Ao incluir serestas, valsas, modinhas, dobrados e marchinhas em sua coleção, atribui-lhes "valor folclórico", atualizando a própria noção do que é " música folclórica brasileira".

Apesar de classificá-las como canções "do tipo burguês”, Luiz Heitor percebeu que seu valor científico advinha da "coletivização" desse repertório, que era amplamente conhecido pelos moradores da cidade de Diamantina. Em suas últimas cartas escritas em Minas, Luiz Heitor defendeu o valor da documentação que produziu de futuras críticas do que chamou de puristas da "ciência folclórica":

Os puristas e quintessenciados da ciência folclórica vão provavelmente ficar muito escandalizados com uma porção de documentos que eu levo gravados, e que podem ser mais classificados de burgueses do que propriamente populares; valsas e modinhas de serenatas, dobrados de banda, marchas de procissão, etc. 


\begin{abstract}
Mas, ou eu não sei folclore, ou folclore é a ciência da tradição, tradição conhecida e aceita por todos. De toda essa música os executantes nem sabem os autores; e todo mundo em Diamantina conhece e canta tais peças. Logo, me parece [texto incompreensível] velhíssimas modinhas, que até numa mesa os convivas cantam várias vozes. Têm a mesma função que as "ballads" inglesas, e outras peças [texto incompreensível] mais refinadas, que evidentemente foram compostas por alguém, mas [das] quais o povo se apossou, tradicionalizando-as, convertendo-as, portanto, em folclore (Azevedo, 1944).
\end{abstract}

De certo modo, Luiz Heitor antecipou as discussões da Carta do Folclore de I95 I, reconhecendo a dimensão processual da criatividade popular, que dentro do contexto de formação do Brasil se dava por apropriação, fusão e reinvenção de formas expressivas oriundas dos "povos formadores do país", "tradicionalizado-as" e "coletivizando-as" (Guerra-Peixe, 2007).

\title{
CONSIDERAÇÕES FINAIS: FONOGRAMAS EM CIRCULAÇÃO
}

Deve-se considerar que as discussões feitas neste artigo se estruturaram a partir de um debate proposto por acadêmicos do campo da antropologia, etnomusicologia e folclore. A vida desses objetos etnográficos fonográficos, porém, nem sempre, termina nas instituições acadêmicas, coleções ou museus. Quando em circulação, esses fonogramas podem ser ressignificados, transformados em arte, mercadorias $^{13}$ (como CDs) ou retornar de diferentes maneiras aos contextos associados a sua criação.

Acompanhar os usos desses fonogramas em diferentes contextos é uma oportunidade de entender mudanças e permanências dos sentidos que tais documentos sonoros assumem. Kopytoff (2008) chamou tal estratégia de "biografia cultural dos objetos": entender como os objetos acabam tendo seus significados alterados e estendidos ao ser "classificados e reclassificados" em diferentes contextos e categorias.

Em I 997, parte da coleção de discos de Luiz Heitor foi lançada comercialmente pela Biblioteca do Congresso Norte-Americano no CD "Music of Ceará and Minas Gerais". A comercialização das gravações permitiu que tais registros circulassem em ambientes e espaços extra-acadêmicos. Durante visitas à cidade de Fortaleza, em 2009 e 201 2, observei que as gravações dos grupos de congo e maracatu ali já estavam em circulação. Compositores/músicos locais como Calé Alencar e Pingo de Fortaleza (2007), por exemplo, incorporam parte do repertório em sua produção artística, fazendo referência aos registros. Além desses artistas, os remanescentes do Maracatu Az de Ouro, documentado por Luiz Heitor, haviam incorporado os fonogramas em acervo histórico. Os integrantes do Az de Ouro tinham os fonogramas como importante referência, principalmente para os tipos de toque de percussão e andamento que utilizavam em suas performances. Argumentavam também que as gravações mostravam como, desde os anos I940, o Az de Ouro possuía estética sonora própria e diferenciada dos demais grupos da cidade de Fortaleza e do estado de Pernambuco. 
No mundo acadêmico, os fonogramas têm sido usados como material de referência em trabalhos como os de Prass (2013) e do músico/pesquisador Spirito Santo (pesquisa não publicada) que retornaram os registros para remanescentes dos grupos documentados. Músicos compositores de formação acadêmica, como Rodrigo Caçapa, têm feito outro tipo de uso. Nesse caso, no projeto "O coco-rojão e as violas eletrodinâmicas: pesquisa e criação", Caçapa, além de transcrever e analisar o repertório coletado por Luiz Heitor, utilizou seus dados organológicos como uma das referências para a construção de violas eletrodinâmicas.

Creio que tais projetos apontam não só para a relevância dos fonogramas de Luiz Heitor, mas também para como as coleções fonográficas, mesmo que pensadas a partir de preceitos científicos, podem ser vistas como obras abertas. Nesse caso, ao sair do arquivo, os fonogramas de Luiz Heitor indicam ter retido propriedades de seu contexto de origem que extravasam as concepções iniciais dadas pelo pesquisador, demonstrando que seus sentidos podem ser tão dinâmicos como os processos criativos da cultura popular.

Recebido em 2/4/I8 | Revisto em I5/5/2018 | Aprovado em 23/5/2018

Felipe Barros é professor do Instituto Federal de Educação, Ciência e Tecnologia do Rio de Janeiro. Bolsista do CNPq (PDJ) e ganhador do Prêmio Produção Crítica em Música Funarte 20I2, publicou Música, etnografia e arquivo nos anos 40: Luiz Heitor Corrêa de Azevedo e suas viagens a Goiás (I942), Ceará (I943) e Minas Gerais (I944). 


\section{NOTAS}

I Tal como aconteceu com os museus dedicados a guardar e expor objetos colecionados nas colônias e nas expedições etnográficas.

2 No arquivo de Berlim encontra-se significativa coleção de instrumentos musicais e música indígena brasileira gravada em I9II-I9I3 por Theodor Koch-Grunberg no norte da Amazônia brasileira, com os índios Makuxi, Taulipan, Tukano, Desana e Yecuanan.

3 Eram antropólogos, folcloristas, etnomusicólogos, musicólogos, linguistas, psicólogos etc.

4 O conceito de prosódia musical engloba a relação entre contorno melódico e acentuação rítmica musical com a acentuação tônica e entonação das palavras de um texto de uma canção ou outra parte vocal, por exemplo.

5 Como demonstro em outra publicação (Barros, 2013), Luiz Heitor muda sua perspectiva em relação aos repertórios musicais folclóricos durante suas viagens etnográficas, assumindo o aspecto dinâmico e processual da composição dos repertórios musicais da cultura popular.

6 Antigo Conservatório de Música, que se tornaria a Escola Nacional de Música da Universidade do Brasil, e, em seguida, Escola de Música da Universidade Federal do Rio de Janeiro.

7 Sá Pereira foi professor de música e compositor cuja obra é relacionada ao Modernismo. Como será demonstrado mais adiante, tornou-se diretor do INM em I938 (Marcondes, 2002).

8 Consultar Andrade (I972) e Travassos (I997 e 2003).

9 Charles Seeger é avô do antropólogo Anthony Seeger e importante pesquisador da área da música nos Estados Unidos; foi um dos fundadores da Society of Ethnomusicology e é identificado como pioneiro no campo da etnomusicologia (Netl, 2005).

Io O técnico nas duas primeiras viagens foi Eurico de Nogueira França, aluno de graduação em piano. Na segunda, Euclides Silva Novo, também professor da Escola Nacional.

I I Vale observar que, nessa época, ainda não existia um Arquivo de Folclore na Escola Nacional de Música, só criado após a segunda viagem de Luiz Heitor, em I943. 
I2 Tal como o caso das coleções etnográficas com objetos da África Central comentado por Fabian (2007: 57).

I3 Vale frisar que, atualmente, as gravações do Arquivo de Berlim, da Missão Folclórica e de Luiz Heitor circulam no comércio em CDs de música étnica, folclórica ou world music.

\section{REFERÊNCIAS BIBLIOGRÁFICAS}

Andrade, Mário de. (1972). Ensaio sobre a música popular brasileira. São Paulo: Livraria Martins Editora.

Aragão, Pedro de Moura. (2005). Luiz Heitor Corrêa de Azevedo e os estudos de folclore no Brasil: uma análise de sua trajetória na Escola Nacional de Música (I932-I947). Dissertação de Mestrado. PPGM/Universidade Federal do Rio de Janeiro.

Araújo, Samuel M. J. (2008). Características e papéis dos Acervos Etnomusicológicos em Perspectiva Histórica, Laboratório de Etnomusicologia da UFRJ. In: Araújo, Samuel; Paz, Gaspar \& Cambria, Vicenzo (orgs.). Música em debate, perspectivas interdisciplinares. Rio de Janeiro: Mauad X/Faperj.

Azevedo, Luiz Heitor Corrêa. (I953). Música popular nordestina. In: Relação de Discos Gravados no Estado do Ceará. Rio de Janeiro: Centro de Pesquisas Folclóricas.

Azevedo, Luiz Heitor Corrêa. (I950). Preâmbulo. In: Relação de Discos Gravados no Estado de Goiás. Rio de Janeiro: Centro de Pesquisas Folclóricas.

Azevedo, Luiz Heitor Corrêa. (I944). Carta escrita durante pesquisa de campo em Minas Gerais. Acervo LabEtno/ UFRJ, MGC 23-25.

Azevedo, Luiz Heitor Corrêa. (1943). A Escola Nacional de Música e as pesquisas de folclore no Brasil. Rio de Janeiro: Centro de Pesquisas Folclóricas da Escola de Música.

Azevedo, Luiz Heitor Corrêa. (1939). Introdução ao curso de Folclore Nacional da Escola Nacional de Música da Universidade do Brasil. In: Revista Brasileira de Música, Rio de Janeiro, 6, p. I-Io. 
Barros, Felipe. (2013). Música, etnografia e arquivo nos anos 40: Luiz Heitor Corrêa de Azevedo e suas Viagens a Goiás (I942), Ceará (I943) e Minas Gerais (I944). Rio de Janeiro: Ed. Multifoco.

Blacking, John. (I979). Some problems of theory and method in the study of musical change. Yearbook of the International Folk Music Council, 1/9, p. I-26.

Brady, Érika. (1999). A spyral way: how the phonograph changed ethnography. Jackson, MS: University Press of Mississippi.

Cavalcanti, Maria Laura Viveiros de Castro et al. (I992). Os estudos de folclore no Brasil. In: Seminário Folclore e Cultura Popular, I. p. IOI-II2. (Série Encontros e Estudos).

Cavalcanti, Maria Laura Viveiros de Catros \& Vilhena, Luís Rodolfo. (I990). Traçando fronteiras: Florestan Fernandes e a marginalização do folclore. Estudos Históricos, Rio de Janeiro, 3, p. 75-92.

Clifford, James. (2002). A experiência etnográfica. Antropologia e literatura no séc. XX. Organizado por José Reginaldo Santos Gonçalves. 2 ed. Rio de Janeiro: Editora da UFRJ.

Cooley, Timothy. (I997). Casting shadows in the field: an introduction. In: Shadows in the field: new perspectives for fieldwork in ethnomusicology. New York: Oxford University Press.

Cunha, Olívia Maria Gomes da. (2004). Tempo imperfeito: uma etnografia no arquivo. Mana - Estudos de Antropologia Social, Io/2, p. 287-322.

Fabian, Johannes. (2007). On recognizing things: the "ethnic artefact" and the "ethnographic object". In: Memory against culture. Arguments and reminders. London: Duke University Press.

Galucio, Ana Vilacy. (2009). Theodor Koch-Grünberg: documentando culturas indígenas no início do século XX. Boletim Música para Emílio Goeldi, Belém, 4/3, p. 553-556.

Gonçalves, José Reginaldo Santos. (2007). Antropologia dos objetos: coleções, museus e patrimônios. Rio de Janeiro: Ministério da Cultura/Iphan. (Coleção museu, memória e cidadania.)

Guerra-Peixe, César. (2007). Sputnik e folclore. In: Araújo, Samuel (org.). Estudos de folclore e música popular urbana. Belo Horizonte: Editora da UFMG. 
Handler, Richard. (I984). On sociocultural discontinuity: nationalism and cultural objetification in Quebec. Current Anthropology, 25/I.

Hardin, James. (2004). Library of Congress American Folklife Center: An Illustrated Guide. With companion CD: "Music and Spoken Word from the Archive of Folk Culture". Washington DC: Library of Congress, American Folklife Center.

Indiana - Archives of Tradicional Music. (20I7). History. Disponível em <http://www.indiana.edu/ libarchm/index. php/about-us/history.html>. Acesso em I2 dez. 2017.

Kartomi, Margaret. (I98I). The processes and results of musical culture contact: a discussion of terminology and concepts. Ethnomusicology, 25, p. 227-250.

Kirshenblatt-Gimblett, Barbara. (1998). Objects of ethnography. In: Destination culture: tourism, museums, and heritage. Berkeley: University of California Press, p. 17-78.

Kopytoff, Igor. (2008). A biografia cultural das coisas: a mercantilização como processo. In: Appadurai, Arjun. A vida social das coisas: as mercadorias sob uma perspectiva cultural. Niterói: UFF, p. 89-I24.

Lira, Mariza. (I953). Iaㅡ exposição de folclore no Brasil: achegas para a história do folclore no Brasil. Rio de Janeiro: Laemmert.

Lomax, Alan. (2003). Folk music in the Roosevelt Era. In: Cohen, Ronald (ed.). Alan Lomax selected writings I934-I997. New York: Routledge.

Makagon, Daniel \& Neumann, Mark. (2009). Recording culture: Audio documentary and the ethnographic experience. Los Angeles: Sage Publications.

Marcondes, Marcos A. (org.). (2002). Enciclopédia da música brasileira: erudita, folclórica e popular. São Paulo: Art/Publifolha.

Mauss, Marcel. (I926). Manuel d'ethnographie. Edição digital. Disponível em <http://classiques.uqac.ca/classiques/ma uss_marcel/manuel_ethnographie/manuel_ethnographie. pdf $>$. Acesso em I7 out. 2008.

Mendonça, Cecília de. (2007). A Coleção Luiz Heitor Corrêa de Azevedo: música, memória e patrimônio. Dissertação de mestrado. Programa de Pós-Graduação em Memória Social/Unirio. 
Merriam, Alan. P. (1964). The anthropology of music. Evanston: Northwestern University Press.

Nettl, Bruno. (2006). O estudo comparativo da mudança musical: estudos de caso de quatro culturas. Anthropológicas, IO/I7/I, P. II-34.

Nettl, Bruno. (2005). The study of ethnomusicology. Urbana: University of Illinois Press.

Nettl, Bruno. (I996). Relating the present to the past: thoughts on the study of musical change and culture change in ethnomusicology. Music \& Anthropology, I. Disponível em <http://www.muspe.unibo.it/period/MA/in$\mathrm{dex} /$ numberi/nettli/ner.htm>. Acesso em 20 out. 2009.

Nettl, Bruno. (I988). The IFMC/ICTM and the development of ethnomusicology in the United States. Yearbook for Traditional Music, 20, p. 19-25.

Nettl, Bruno. (1985). The Western impact on world music. New York: Schirmer.

Pingo de Fortaleza. (2007). Maracatu Az de Ouro: 70 anos de memórias, loas e batuques. Fortaleza: Omni.

Pereira, Edmundo \& Pacheco, Gustavo. (2008). Rondônia I9I2: gravações históricas de Roquette-Pinto. Rio de Janeiro: Museu Nacional. (Coleção Documentos Sonoros)

Pinto, Tiago de Oliveira (2004). Cem anos de Etnomusicologia e a "Era fonográfica" da disciplina no Brasil. Disponível em <http://sonsdobrasil.blogspot.com.br/2005/ro/ etnomusicologia-ıoo-anos.html>. Acesso em 20 jan. 2018. Pinto, Tiago de Oliveira (200I). Som e Música. Questões de uma antropologia sonora. (200I). Revista de Antropologia, $44 /$ I.

Prass, Luciana. (2013). Maçambiques, quicumbis e ensaios de promessa: musicalidades quilombolas no Sul do Brasil. Porto Alegre: Editora Sulina.

Sandroni, Carlos. (2008) [1938]. Missão de pesquisas folclóricas: música tradicional do Norte e Nordeste. Revista do IEB, 46.

Seeger, Anthony. (2003). I found it, how can I use it? Dealing with the ethical and legal constraints of Information Access. Disponível em <http://ismir2003.ismir.net/papers/Seeger.PDF>. Acesso em set. 2006. 
Seeger, Anthony. (200I). Intellectual property and audiovisual archives and collections. In: Folk heritage collections in crisis. Washington DC: Council on Library and Information Resources, p. 36-47. Disponível em <http://www.loc. gov/folklife/fhcc/propertykey.html>. Acesso em ago. 2006. Seeger, Anthony. (I986). The role of sound archives in ethnomusicology today. Ethnomusicology, 30/2, p. 26I-276. Sterne, Jonathan. (2003). The audible past: cultural origins of sound reproduction. Durham: Duke University Press.

Stocking, George W. (1983). Observers observed - essay on ethnographic fieldwork. Madison: The University of Wisconsin Press.

Travassos, Elizabeth. (2003). Esboço de balanço da etnomusicologia no Brasil. Opus, 1/9. Disponível em <http:// www.anppom.com.br/opus/opusg/sumario.htm>. Acesso em 20 out. 2009.

Travassos, Elizabeth. (1997). Os mandarins milagrosos: arte e etnografia em Mário de Andrade e Bela Bartók. Rio de Janeiro: Zahar.

Toni, Flávia. (1985). A Missão de Pesquisas Folclóricas do Departamento de Cultura. São Paulo: Centro Cultural São Paulo.

Vilhena, Luís Rodolfo. (I997). Projeto e missão: o movimento folclórico brasileiro I947-I964. Rio de Janeiro: Funarte.

Zamith, Rosa Maria Barbosa. (I992). A Escola de Música da UFRJ e o estudo e pesquisa do folclore musical. Problemas e perspectivas. Anais do Simpósio Nacional de Ensino e Pesquisa de Folclore. São José dos Campos: Fundação Cultural Cassiano Ricardo, p.I35-I45. 
Palavras-chave

Fonogramas;

coleções fonográficas; etnografia;

folclore;

Luiz Heitor Corrêa de Azevedo.

\section{ARQUIVOS E OBJETOS SONOROS ETNOGRÁFICOS: A COLEÇÃO FONOGRÁFICA DE LUIZ HEITOR CORRÊA DE AZEVEDO}

\section{Resumo}

O artigo problematiza o papel das coleções fonográficas e uso de gravações sonoras em pesquisas etnográficas. A primeira parte trata do impacto da invenção do fonógrafo em pesquisas etnográficas e investiga os diferentes sentidos atribuídos aos arquivos fonográficos pela antropologia e etnomusicologia. A segunda parte consiste num relato de pesquisa sobre o acervo fonográfico de Luiz Heitor Corrêa de Azevedo, formado entre I942 e I944, a partir de um projeto de documentação de "música folclórica brasileira" nos estados de Goiás, Ceará e Minas Gerais. A partir dessa experiência de pesquisa abordam-se lógicas de colecionamento e metodologias em um projeto baseado em documentação fonográfica, nos anos 40, no Brasil, bem como os diferentes sentidos atribuídos a fonogramas de Luiz Heitor em circulação por contextos não acadêmicos.

\section{ARCHIVES AND ETHNOGRAPHIC SOUND OBJECTS: THE LUIZ HEITOR CORRÊA DE AZEVEDO COLLECTION}

Keywords

Phonograms; sound archives;

ethnography;

folkore;

Luiz Heitor Corrêa de Azevedo.

\section{Abstract}

The article concerns the role of sound archives and the use of sound recordings in ethnographic research. The first part presents a discussion of the impact of the invention of the phonograph in ethnographic research and investigates the different meanings attributed to phonographic archives by anthropology and ethnomusicology. The second part is a research report about Luiz Heitor Corrêa de Azevedo's phonographic collection, produced between I942 and I944, during his ethnographic trip to the states of Goiás, Ceará and Minas Gerais. Using Luiz Heitor's research as a case study, the article addresses the rationale and methodology behind projects of phonographic documentation in the I 940 s as well as the different meanings attributed to Luiz Heitor's phonograms when they circulate in non-academic contexts. 